\title{
A docência nas séries iniciais: formação e prática pedagógica de professores de Matemática
}

\author{
Teaching in the initial series: training and pedagogical practice of Math teachers
}

Enseigner dans la série initiale: formation et pratique pédagogique des enseignants Mathématiques

\author{
Cristiana Barra Teixeira ${ }^{1}$ \\ Universidade Federal do Piauí \\ Guilherme Saramago de Oliveira ${ }^{2}$ \\ Universidade Federal de Uberlândia
}

Resumo: Com objetivo de discorrer sobre a docência nas séries iniciais tecendo reflexões sobre a formação e a prática pedagógica de professores de Matemática, desenvolvemos este estudo bibliográfico no encalço da questão: Quais as nuanças da docência nas séries inicias tendo em vista as marcas da formação e da prática pedagógica de professores de Matemática? Em torno desse propósito a tessitura discute a docência nos anos iniciais pontuando que a polivalência exercida pelos professores é permeada por lacunas da formação e nesse sentido, os profissionais enfrentam desafios importantes. Pontuamos que o conhecimento matemático tem grande importância na formação desses professores, sem dissociar-se da didática. É preciso fazer matemática, saber como e por quê ensinar essa disciplina. A formação centrada no desenvolvimento da pesquisa, da investigação e do questionamento busca melhorar a habilidade de ensinar. Na verdade, ensinar só se aprende ensinando, e toda prática tem uma teoria que a sustenta. É importante que a teoria sobre a qual nos embasemos, potencialize em nós a capacidade de avaliação e raciocínio crítico.

Palavras-chave: Docência nas séries iniciais. Formação de professores. Prática pedagógica de Matemática

\begin{abstract}
With the purpose of discussing teaching in the initial grades, reflecting on the formation and pedagogical practice of mathematics teachers, we developed this bibliographic study in the pursuit of the question: What are the nuances of teaching in the initial grades in view of the marks of formation and pedagogical practice of mathematics teachers? Around this purpose, the teaching discusses teaching in the initial years, pointing out that the polyvalence exercised by teachers is permeated by training gaps and in this sense, professionals face important challenges. We point out that mathematical knowledge has great importance in the formation of these teachers, without dissociating from didactics. It is necessary to do math, to know how and why to teach this discipline. Training focused on the development of research, research and questioning seeks to improve the ability to teach. In fact, teaching only learns by teaching, and every practice has a theory that supports it. It is important that the theory upon which we are based may potentiate in us the capacity for evaluation and critical reasoning.
\end{abstract}

\footnotetext{
${ }^{1}$ Mestre em Educação pela Universidade Federal do Piauí (UFPI). Doutoranda em Educação da Universidade Federal de Uberlândia (UFU). Professora da Universidade Federal do Piauí (UFPI/CSHNB). E-mail: cristiana_barra@yahoo.com.br

${ }^{2}$ Doutor em Educação pela Universidade Federal de Uberlândia (UFU). Professor Programa de Pós-graduação em Educação (PPGED/UFU) e da Faculdade de Educação (FACED/UFU).E-mail: gsoliveira@ufu.br
} 
Keywords: Teaching in the initial grades. Teacher training. Pedagogical Practice of Mathematics

Résumé: Afin de discuter de l'enseignement dans les premières années de tissage réflexions sur la pratique et l'enseignement de formation des enseignants de mathématiques, nous avons développé cette étude bibliographique sur les talons de la question: Quelles sont les nuances de l'enseignement en première série étant donné les marques de formation et pratique pédagogique des professeurs de mathématiques? Autour de cet effet, le tissu discute l'enseignement dans les premières années soulignant que la polyvalence exercée par les enseignants est pénétrée par des lacunes dans la formation et dans ce sens, les professionnels sont confrontés à des défis importants. Nous avons fait remarquer que la connaissance mathématique est d'une grande importance dans la formation de ces enseignants, ne se dissocie pas de l'enseignement. Il faut faire des maths, savoir comment et pourquoi enseigner cette discipline. La formation axée sur le développement de la recherche, de la recherche et du questionnement vise à améliorer la capacité d'enseigner. En fait, l'enseignement n'apprend que par l'enseignement, et chaque pratique a sa propre théorie. Il est important que la théorie sur laquelle les embasemos, l'effet de levier en nous la capacité d'évaluer et de la pensée critique.

Mots-clés: Enseignement dans les notes initiales. Formation des enseignants. Pratique pédagogique des mathématiques

\section{Introdução}

A tessitura desse texto tem como objetivo discorrer sobre a docência nas séries iniciais tecendo reflexões sobre a formação e a prática pedagógica de professores de Matemática. Sua realização parte da seguinte questão norteadora: Quais as nuanças da docência nas séries inicias tendo em vista as marcas da formação e da prática pedagógica de professores de Matemática?

Trata-se de um estudo bibliográfico fundamentado nas contribuições de: Nóvoa (1992), Mellouki e Gauthier (2004), Tardif (2002), Cicillini e Silva (20120), Costa (2010), Gauthier et al (1998) dentre outros. O embasamento teórico utilizado busca a constatação de que os autores pesquisados oferecem subsídios indispensáveis para o alcance do objetivo proposto em torno da questão investigada.

O ensino da Matemática nas séries iniciais do Ensino Fundamental conquista nosso interesse de estudo porque nos interessamos por esta área científica, sua importância, suas contribuições para a vida cotidiana e principalmente porque enquanto disciplina escolar, a Matemática tem sido uma disciplina muito falada, à qual facilmente se infere, do insucesso 
escolar, seja pelos alunos, seja pelos professores ou por quaisquer pessoas que, de uma forma direta ou indireta, entram em contato com a Matemática.

O ensino de Matemática tem particularidades relacionadas à formação docente e ao contexto da prática pedagógica no qual ele acontece e sobre o qual ela provoca efeitos. Nesse compasso, essa tessitura organiza-se numa discussão sobre as nuanças da docência nas séries iniciais e reflexões sobre formação e prática de professores de matemática.

\section{A docência nas séries iniciais: demandas do ensino de Matemática}

Os professores das séries iniciais, conhecidos como professores generalistas ou polivalentes porque são professores de todas as disciplinas curriculares, deixam a formação inicial com uma bagagem mínima de habilidades, saberes e conhecimentos sobre Matemática. Esses professores reservam dúvidas, conflitos, desafios, receios acerca do ensino de Matemática para a própria prática pedagógica.

Os desafios da formação matemática dos professores de polivalência passaram a ser objeto de estudos e pesquisa que evidenciam a estreita relação entre os problemas formativos e os problemas de ensino e aprendizagem em Matemática. As orientações cabíveis na formação inicial têm importância, inclusive, no reconhecimento das dificuldades vivenciadas pelos professores. Sabemos que a formação inicial não pode sozinha tornar o professor pronto, completo, até porque o processo de formação deve ser sempre continuado e o desenvolvimento profissional deixa o professor perceber que sempre poderá retomar sua posição de sujeito em formação a partir da reflexão sobre sua prática. Mas essa formação precisa deixar possibilidades para que novos caminhos possam ser trilhados.

Nesse percurso, ser professor/a demanda interesse em aprender a ser e a fazer docência, pois a escola está inserida em um contexto histórico e político que precisa ser conhecido e abordado. A Escola é uma comunidade de aprendizagem e de diversidades onde a produção de conhecimento sustenta sua função social. Sobre esses enlaces, Costa (2010, p. 87) afirma:

[...] é importante que ele seja um ávido aprendiz, tenha a capacidade de perceber as necessidades do contexto, domine os conteúdos de sua área específica e possa adaptá-los aos diversos tipos de aluno presentes nessa Escola, que é democratizada e voltada para todos. Em relação ao conteúdo programático a ser desenvolvido com os alunos, deve ser visto pelos educadores como um meio e não um fim em si mesmo, ou seja $[\ldots .$.$] .$ 
Crianças e adultos têm dificuldades matemáticas o que implica dizer que muitos dos que se formam professores sentem dificuldades matemáticas e, consequentemente, tem dificuldade de ensinar a Matemática e acabam produzindo problemas na aprendizagem matemática de seus alunos e até mesmo na maneira como eles passarão a perceber a Matemática na continuidade de seus estudos e na própria vida em sociedade.

Segundo Gomes (2002, p. 363), “[ [...] a aprendizagem matemática ainda se constitui em um grande problema, tanto para as crianças quanto para os professores que estão sendo formados nos cursos de Pedagogia, o que favorece a criação de sujeitos fóbicos e analfabetos matematicamente".

Pavanello (2001) acredita que muitas das dificuldades das crianças em relação à Matemática podem estar relacionadas à atuação didática do professor. Para Gomes (2002), portanto, é importante considerar que nenhum professor consegue criar, planejar, gerir e avaliar situações didáticas eficientes sem que tenha um domínio dos conteúdos específicos das áreas de conhecimentos. A autora defende que a aquisição e a compreensão de conceitos matemáticos fundamentais deveriam ocorrer nos cursos de formação inicial.

A formação, segundo Loureiro (2004, p. 93-94) deve favorecer o desenvolvimento de concepções, atitudes e capacidades positivas, como o "gosto por aprender, a autonomia, a vontade e o gosto por enfrentar dificuldades, a persistência, a valorização da ajuda de outro, a capacidade de procurar ajuda, a confiança nas ideias próprias”. Essa formação deve encorajar o futuro professor a refletir, questionando suas crenças e concepções, de forma que possa vir a alterá-las. Assim, possibilitará a esse professor romper com várias crenças construídas e ver a Matemática de uma maneira diferente, construindo novas concepções sobre fazer, aprender e ensinar matemática.

\section{Sobre formação e prática pedagógica: ser professor na atualidade}

Os conhecimentos do professor sobre os objetos de ensino devem incluir os conceitos das áreas de ensino definidos para a escolaridade na qual ele irá atuar. Porém, eles precisam ir além, tanto no que se refere à profundidade desses conceitos como à sua historicidade, sua articulação com outros conhecimentos e o tratamento didático, ampliando assim seu conhecimento da área. Falamos de uma formação ampla que, segundo Garcia (1992, p.26) trata-se de: 
Uma área de conhecimentos, investigação e de propostas teóricas e práticas que no âmbito da didática e da organização escolar, estuda os processos a partir dos quais os professores, em formação ou em exercício, se aplicam individualmente ou e equipe, em experiências de aprendizagem através das quais adquirem ou melhoram os seus conhecimentos, competências e disposições, e que lhes permite intervir profissionalmente no desenvolvimento do seu ensino, do currículo e da escola, com objetivo de melhorar a qualidade da educação, que os alunos recebem.

A formação de professores, na atualidade, não pode mais está limitada à dimensão instrumental, pelo contrário, precisa ultrapassá-la em busca de novas perspectivas envolvidas com a "ressignificação da cultura profissional, valorizando práticas docentes participativas, reflexivas e, sobretudo, críticas." (BRITO, 2006, p.41). As exigências sociais condicionam a necessidade de novos olhares sobre formação de professores.

$\mathrm{Na}$ contemporaneidade, são abundantes as discussões acerca dos processos formativos de professores. Vivenciamos avalanches de produção tecnológicas, logo, também, de produção de informações, muitas e diversas informações. Nesse contexto, o acesso às tecnologias e a todos os seus produtos e subprodutos é apenas uma questão de tempo, de rápido tempo. Nessa turbulência social encontramos nossa escola, nossos alunos, e, evidentemente nossos professores. Mas, precisamos atentar em torno desta última figura e tecer questionamentos sobre seu papel na sociedade, na escola, na vida de cada aluno. Precisamos refletir sobre o professor que se forma para atuar nesse contexto, assim como o professor que já está formado e atua nesse contexto.

Imbernón (2010, p.27) afirma que a formação de professores “[ [...] deve assumir parcelas de mudança e inovação...”. Compreendemos que essa mudança e essa inovação devem ser almejadas pelos próprios professores, os sujeitos ativos da própria formação, desse modo, entenderemos conforme Nóvoa (1997, p. 28) que “[...] a formação não se faz antes da mudança, faz-se durante, produz-se nesse esforço de inovação e de procura dos melhores percursos para a transformação da escola".

Estamos falando de ações coletivas com reflexos individuais, ou seja, o trabalho e o processo formativo precisam ter dimensão coletiva, participativa. O professor forma-se ao formar o seu contexto de atuação ao mesmo tempo em que tal contexto exerce sobre sua formação individual influência equivalente ao seu esforço desprendido para mudar, melhorar, atualizar, inovar, tornar sua prática crítica e consciente. Assim, afirmamos que a formação docente é norteada pela prática pedagógica desenvolvida pelo o professor na mesma proporção em que esta prática é alimentada pela própria formação, como num ciclo de energia dentro de um ecossistema. Esta é a forma geradora do conhecimento, é através da prática que surgem ou 
se constroem competências para a mobilização do pensamento pedagógico reflexivo, através de um processo contínuo.

Nóvoa (1992) evidencia que o professor que deseja desenvolver uma prática pedagógica pela prática social, opta conscientemente pelo desejo de renovar sua atuação, de promover transformação, implementando novos valores na escola e, consequentemente, na aula. Essa renovação é pautada na necessidade de aprender constantemente. A esse respeito, Guarnieri (2005) pontua que no exercício da profissão o processo de tornar-se professor é um aprendizado a partir de seu exercício o que possibilita configurar como vai sendo constituído o processo de aprender a ensina.

A compreensão desse debate sobre formação de professores nos leva a princípios que não podem ser deixados a segundo plano, pois toda formação deve ser um processo contínuo de aprendizagens, daí a necessidade de estudos continuados durante toda a carreira profissional. O professor forma-se numa instituição de ensino para exercer sua profissão em uma instituição de ensino, passa, dessa maneira, a fazer parte desta instituição, de sua organização e principalmente de sua funcionalidade.

A instituição palco do desempenho do profissional professor, a escola, tem vida, está inserida na sociedade, interfere na dinâmica social, recebe interferência dessa mesma dinâmica, logo precisa estar conectada com ela, atualizando-se para atender suas demandas e, essencialmente, transformá-la.

O profissional consciente de sua formação possivelmente consegue refletir sobre as habilidades necessárias ao exercício de sua profissão, assim como, seja capaz de novos conhecimentos sobre ensino e aprendizagem. Estamos falando de um professor agente de uma formação reflexiva, desde que esta reflexão seja uma prática social a partir e para os condicionantes sociais do ensino, como define Zeichner (2003).

Nessa trilha, Cicillini (2010, p. 35) aponta que o professor deve construir concepção do que é ensinar e do que é aprender e que um desafio é a compreensão do processo de construção, de produção de conhecimento do ser humano, sendo preciso captar a lógica de como apreendem conhecimento, rompendo com referencial de transmissor de conhecimento, integrando a sua prática reflexões filosóficas, sociológicas, antropológicas dentre outras numa ruptura da fragmentação do conhecimento. “[ [...] o que um professor é está diretamente relacionado àquilo que faz e às suas experiências de vida, ou seja, o que ele é em cada momento.”

Entende-se, portanto, o ensino como prática cultural e política que não tangencia apenas o transmitir informações, mas as práticas que a produzem. Nesse enlace, os postulados 
de Mellouki e Gauthier (2004, p.543) afirmam que o ensino é uma profissão tão paradoxal e complexa que:

[...] quem a exerce deveria possuir, ao mesmo tempo, as qualidades de estrategista e de tático de um general do exército; as qualidades de planejador e de líder de um dirigente de empresa; a habilidade e a delicadeza de um artesão; a destreza e a imaginação de um artista; a astúcia de um político; o profissionalismo de um clínico-geral; a imparcialidade de um juiz; a engenhosidade de um publicitário; os talentos, a ousadia e os artifícios de um ator; o senso de observação de um etnólogo; a erudição de um hermeneuta; o charme de um sedutor; a destreza de um mágico e muitas outras qualidades cuja lista seria praticamente ilimitada.

Para os autores o professor é um intelectual, mediador, intérprete e tradutor de conhecimentos, técnicas e procedimentos pedagógicos, portador da cultura, agente de socialização e guardião responsável pela consolidação das regras de conduta e maneiras de ser valorizadas pela escola e pela sociedade.

Do ponto de vista da competência profissional o que diferencia o professor de outros agentes que atuam na distribuição cultural não é o domínio da disciplina, embora este seja indispensável ao exercício profissional, mas o que lhe é peculiar "é a posse de saberes e de habilidades que lhe permitem garantir a aprendizagem da disciplina e a transmissão de uma concepção específica do mundo”. O professor desempenha o papel fundamental de herdeiro, crítico e intérprete da cultura, cabendo ao mesmo despertar nos alunos o desejo de aprender e de exercer seu próprio julgamento. Esse mestre é como um guia que durante uma viagem

[...] lança um olhar ora grave ora jocoso sobre a paisagem que conhece tão bem e partilha com seus passageiros, que são seus alunos, seu entusiasmo e sua sede de conhecimento. Mas nunca lhes impõe suas maneiras de ver e de compreender a paisagem. Propõe-lhes itinerários que já explorou, mas nunca lhes revela as surpresas que os esperam no fim da trilha (MELLOUKI E GAUTHIER, 2004, p.558).

O professor enquanto um profissional cujo processo formativo requer a conquista de saberes intrínsecos a sua profissão dada a essência do que ele faz, ou seja, ensinar. Mas, é necessário enfatizar que os saberes específicos da profissão professor estão conectados ao ensino e à aprendizagem, interagindo de forma real com o contexto escolar onde o ensino e a aprendizagem acontecem e, evidentemente, na interação com seus alunos.

A essa maneira Tardif (2002) considera que o professor, ao realizar seu trabalho, se apoia nos conhecimentos disciplinares, didáticos e pedagógicos adquiridos na escola de formação; nos conhecimentos curriculares veiculados em programas e livros didáticos, mas considera ainda que eles são provenientes também de sua cultura pessoal, de sua história de 
vida e de sua escolaridade anterior e no seu próprio saber proveniente de experiências profissionais.

O conhecimento profissional dos professores se tece por meio da participação nas práticas educativas, ou seja, nos processos de formação de professores a prática torna-se um elemento essencial. Entretanto, a prática por si só não garante a qualidade na formação. Contudo, o processo de formação de professores nos diversos níveis (formação inicial, formação contínua, formação especializada) é um processo de desenvolvimento profissional que envolve o desenvolvimento de potencialidades de cada professor e a construção de novos saberes marcados pelas dinâmicas sociais.

Trata-se da formação no contexto escolar, onde e exclusivamente é possível articular os saberes subsidiados pela instituição formadora com os saberes da experiência docente. Por isso falam-se tanto em formação na escola, pois é nesse contexto que o professor experimenta saberes, acrescenta novos ingredientes para reformulá-los ou refutá-los, semeia informações que darão origem a novos saberes, enfim.

O equilíbrio entre formação e prática pedagógica é necessário e a esse respeito Guarnieri (2005) chama atenção para o reducionismo perigoso de atribuir excessivo valor à formação acadêmica em detrimento da importância da prática pedagógica ou vice e versa. Fazse preciso compreender que a experiência docente é um elemento indispensável para o desenvolvimento profissional do professor, assim como, também, é a sua formação. Brito (2007, p.50) acrescenta que há valorização dos "saberes da experiência, apresentando como novo paradigma formativo a perspectiva reflexiva."

Nesse debate, temos que a perspectiva reflexiva de formação docente é delineada pela necessidade do próprio professor perceber-se como um profissional reflexivo, capaz construir o saber no cotidiano escolar de seu fazer pedagógico, refletindo continuamente na ação, (BRITO, 2006).

A perspectiva reflexiva crítica é tomada por Nóvoa (1992) como processo que fornece aos professores meios de pensar com autonomia no contexto de auto formação, usufruindo de liberdade e criatividade. Tardif (2000) contribui com essa discussão acrescentando que a prática docente é o palco e o cenário de produção de saberes relativos à profissão. Para este autor, cabe ao professor tornar-se sujeito do conhecimento detendo saber específico e intrínseco ao seu fazer pedagógico.

Por sua vez, Cicillini e Silva (2012) apontam que os/as professores/as são autores/as da própria formação, logo, são responsáveis pelas articulações e tomadas de decisão, seja de 
processos relativos ao trabalho da escola, seja com as instâncias formadoras parceiras. Nos processos formativos as experiências e aprendizagens são compartilhadas mutuamente e balizadas na interação de saberes. Nesse primo, dizem que é preciso enunciar os elementos que fortalecem a prática educativa como o diálogo entre os saberes e entre as disciplinas - diálogo interdisciplinar e o trabalho coletivo., propondo, numa perspectiva interdisciplinar, o desafio de dialogar com os contextos sociais, com o ambiente e as tecnologias.

Então nossa formação, segundo Pimenta (1999, p.30) requer mobilização de “[...] saberes da nossa prática reflexiva”, assim como de "saberes especializados" e "saberes de uma militância pedagógica”. Percebemos que a prática pedagógica é também uma referência na formação docente, pois nos formamos para exercício da prática docente e atuamos profissionalmente para produzirmos nossa formação.

Essa relação teoria e prática, fundamental no processo de formação docente, é estudada por Fiorentini et al (1998, p.319) nos oferecendo a seguinte contribuição:

O saber do professor, portanto, não reside em saber aplicar o conhecimento teórico ou científico, mas sim, saber negá-lo, isto é, não aplicar pura e simplesmente este conhecimento, mas transformá-lo em saber complexo e articulado ao contexto em que ele é produzido.

Mais uma vez encontramos respaldo para afirmar que o professor é o agente principal de sua prática pedagógica assim como de sua formação. No emaranhado de suas atribuições vai construindo caminhos, refletindo sobre sua construção, traçando novas alternativas, e, nesse, indo e vindo, o professor vai conhecendo, aprendendo a conhecer, a ser, a saber e a fazer. Percebemos, dessa maneira, que a ação docente recorre à mobilização de saberes inseridos no contexto da sala de aula, produzidos ali, a partir das relações interpessoais estabelecidas com os alunos e de tantas demandas que vão surgindo na dinâmica da sala de aula.

Querendo encerrar essas considerações sobre formação de professores diante das perspectivas sociais atuais recorremos às contribuições de Pimenta (1999) no que diz respeito ao saber docente enquanto saber fazer a partir da articulação entre outros saberes da formação e da prática. A autora concretiza o esclarecimento de que os conhecimentos teóricos são construídos e ou reconstruídos na própria ação docente. 


\section{Considerações finais}

Considerando o objetivo de discorrer sobre a docência nas séries iniciais tecendo reflexões sobre a formação e a prática pedagógica de professores de Matemática, nesse estudo bibliográfico, pontuamos algumas considerações:

Nos anos inicias, o ensino de Matemática, via de regra, é responsabilidade do professor de polivalência, ou seja, o docente que ministra todas as disciplinas. Contudo, esses profissionais enfrentam, dentre tantos desafios, as lacunas deixadas pela formação que lhes proporciona uma bagagem mínima de habilidades, saberes e conhecimentos sobre Matemática. Esses professores reservam dúvidas, conflitos, desafios, receios acerca do ensino de Matemática para a própria prática pedagógica.

As disciplinas relacionadas à Matemática na formação de professores têm reconhecida contribuição, embora seja necessário refletir sobre essa para a formação matemática de professores das séries iniciais do Ensino Fundamental. Por outro lado, os alunos-professores necessitam de conhecimentos matemáticos básicos para lecionar essa disciplina específica que lhes compete na sua função, mas a construção desses conhecimentos pode não ser garantida pela formação. De fato, o conhecimento matemático é imprescindível para o ensino dessa matéria.

O conhecimento matemático tem grande importância na formação desses professores, sem dissociar-se da didática. É preciso fazer matemática, saber como e porquê ensinar essa disciplina. A formação centrada no desenvolvimento da pesquisa, da investigação e do questionamento busca melhorar a habilidade de ensinar. Na verdade, ensinar só se aprende ensinando, e toda prática tem uma teoria que a sustenta. É importante que a teoria sobre a qual nos embasemos, potencialize em nós a capacidade de avaliação e raciocínio crítico.

O processo de formação inicial em relação à Matemática é marcado por diversas dificuldades que estão relacionadas à caracterização da prática formadora, às orientações matemáticas para a prática docente do futuro professor e à percepção da relação teoria e prática durante a formação inicial. Dada essa formação inicial, ainda deficitária, sobretudo no atendimento das demandas da prática pedagógica assim como, também, do ideal preparo dos futuros professores para uma prática pedagógica reflexiva. 


\section{Referências}

BRITO A. E. Formar professores: rediscutindo o trabalho e os saberes docentes. In: MENDES SOBRINHO, J. A. M. C; CARVALHO, M. A. Formação de professores e práticas docentes: olhares contemporâneos. Belo Horizonte: Autêntica. 2006, p.41-53.

Sobre a formação e a prática pedagógica: o saber, o saber-ser e o saber-fazer no exercício profissional. In: MENDES SOBRINHO, José Augusto de Carvalho (Org.). Formação e prática pedagógica: diferentes contexto e análises. Teresina: EDUFPI, 2007. p.47-62.

CICILLINI, G. A.; SILVA, E. P. Q. A formação de professores em acontecimentos: a produção de saberes escolares nas ciências naturais no nível médio. In: PUENTES, R. V.; LONGAREZI, A. M.; AQUINO, O. F. (Org.). Ensino médio: estado atual, políticas e formação de professores. Uberlândia: EDUFU, 2012, p.287-305.

CICILLINI, Graça Aparecida. Professores universitários e sua formação: concepções de docência e prática pedagógica. In: NOVAIS, Gercina Santana; CICILLINI, Graça Aparecida (Org.). Formação docente e práticas pedagógicas: olhares que se entrelaçam. Araraquara, SP: Junqueira \& Martins; Belo Horizonte, MG: FAPEMIG, 2010. ISBN 978-85-86305-83-2; p. $19-43$.

COSTA, Nielce Meneguelo Lobo. Reflexões sobre Tecnologia e Mediação Pedagógica na Formação do Professor de Matemática. In: BELINE, Willian; COSTA, Nielce Meneguelo Lobo (Orgs.). Educação Matemática, Tecnologia e Formação de Professores: algumas reflexões. Campo Mourão: Editora da FECILCAM, 2010, p.85-116.

FIORENTINI, D.; SOUZA e MELO, G. F. Saberes docentes: Um desafio para acadêmicos e práticos in: GERALDI, C. (Org). Cartografias do trabalho docente: Professor (a) -pesquisador (a). Campinas: Mercado das Letras, ALB, 1998. p.307- 355.

GARCIA, C. M. A formação de professores: novas perspectivas baseadas na investigação sobre o pensamento do professor. In: NÓVOA, A. (Org.). Os professores e a sua formação. Lisboa: Dom Quixote, 1992. p. $51-75$.

GAUTHIER, C. et al. Por uma teoria da pedagogia: pesquisas contemporâneas sobre o saber docente. Ijuí: Ed. UNIJUÍ, 1998

GUARNIERI, R. (Org.). Aprendendo a ensinar: o caminho nada suave da docência. Campinas: Autores Associados, 2005.

GOMES, M. G. Obstáculos epistemológicos, obstáculos didáticos e o conhecimento matemático nos cursos de formação de professores das séries iniciais do ensino fundamental. Contrapontos - ano 2 - n. 6 - p. 423-437 - Itajaí, set./dez. 2002.

IMBERNÓN, F. A formação continuada de professores. Porto Alegre: Artmed, 2010.

LOUREIRO, M. I. O desenvolvimento da carreira dos professores. In: ESTRELA, M.T. (Org.). Viver e construir a profissão docente. Porto: Porto Editora, 2004. p.117-160. 
MELLOUKI, M'Hammed; GAUTHIER, Clemont. O professor e seu mandato de mediador, herdeiro, intérprete e crítico. Educação $\mathcal{E}^{\circ}$ Sociedade, Campinas, v.25, n. 87, p.537571 ,maio/ago.2004.

NÓvOA, A. (Org.). Vidas de Professores. Porto: Porto Editora, 1992.

- Os professores e a sua formação. Publicações Dom Quixote Instituto de Inovação Educacional. Lisboa, 1997

PAVANELLO, R. M. Geometria: atuação de professores e aprendizagem nas séries iniciais. In: Anais do I Simpósio Brasileiro de Psicologia da Educação Matemática. Curitiba: 2001, p. 172 183.

PIMENTA, S. G. (Org). Saberes pedagógicos e atividade docente. São Paulo: Cortez, 1999.

TARDIF, M. Saberes docentes e formação profissional. 2. ed. Petrópolis: Vozes, 2002.

ZEICHNER, K. M. Para além da divisão entre professor-pesquisador e pesquisador acadêmico. In: GERALDI, C. FIORENTINI, D. PEREIRA, E. (Org). Cartografias do trabalho docente: professor (a) -pesquisador (a). 2. ed. Campinas, SP: Mercado de Letras 2003. p. 207236. 